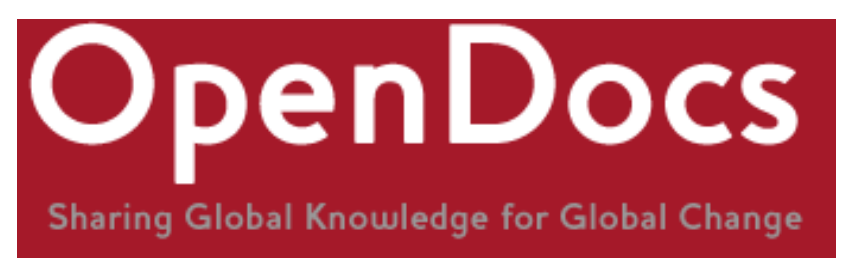

Title: Prescriber and Dispenser Perceptions About Antibiotic Use in Acute Uncomplicated Childhood Diarrhea and Upper Respiratory Tract Infection in New Delhi: Qualitative Study

Citation: Kotwani. A., Holloway. K. and Jhamb. U. (2017) 'Prescriber and Dispenser Perceptions About Antibiotic Use in Acute Uncomplicated Childhood Diarrhea and Upper Respiratory Tract Infection in New Delhi: Qualitative Study' Indian J Pharmacol; 49:419-31

Official URL: https://doi.org/_10.4103/ijp.IJP_508_17

\title{
More details/abstract
}

The objective of the study was to explore the prescribing practices, knowledge, and attitudes of primary care doctors and community pharmacists, regarding antibiotic use in acute upper respiratory tract infections (URTI) and diarrhea in children to better understand causes of misuse and identify provider suggestions to change such behavior. RESULTS: All groups admitted to overusing antibiotics, GPs appearing to use more antibiotics than GDs and pediatricians for URTI and diarrhea in children. Pharmacists copy the prescribing of neighborhood doctors. Antimicrobial resistance (AMR) knowledge was poor for all stakeholders except pediatricians. Causes for prescribing antibiotics were patient pressure, profit motive, lack of follow-up and in addition for GDs, workload, no diagnostic facility, and pressure to use near-expiry medicines. Knowledge was gained through self-experience, copying others, information from pharmaceutical companies, and for some, training, continuous medical education/conferences. All groups blamed other professional groups/quacks for antibiotic overuse. Interventions suggested were sensitizing and empowering prescribers through training of providers and the public about the appropriate antibiotic use and AMR and implementing stricter regulations.

Version: Version of record

Terms of use: This is an open access article distributed under the terms of the Creative Commons Attribution-NonCommercial-ShareAlike 4.0 License, which allows others to remix, tweak, and build upon the work non-commercially, as long as the author is credited and the new creations are licensed under the identical terms.

This is a download from OpenDocs at the Institute of Development Studies

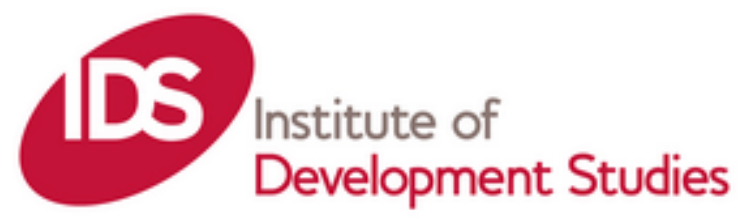




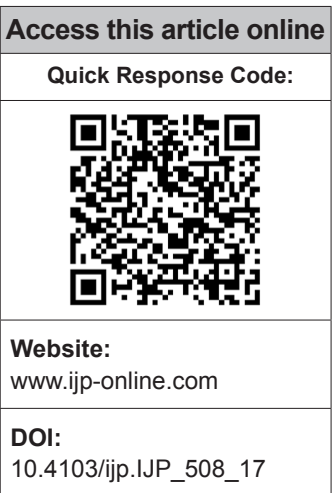

Department of Pharmacology, V. P. Chest Institute, University of Delhi, ${ }^{1}$ Department of Anthropology, University of Delhi, ${ }^{2}$ Department of Paediatrics, L. N. Hospital, New Delhi, ${ }^{3}$ Indian Institute of Health Management Research (IIHMR) University,

Jaipur, Rajasthan, India, ${ }^{4}$ Department of Health

and Nutrition, Institute of Development Studies, University of Sussex, Brighton, UK

Address for correspondence:

Prof. Anita Kotwani,

Department of

Pharmacology,

V. P. Chest Institute,

University of Delhi, Delhi - 110 007, India.

E-mail: anitakotwani@ gmail.com

Submission: 12-09-2017 Accepted: 11-01-2018

Prescriber and dispenser perceptions about antibiotic use in acute uncomplicated childhood diarrhea and upper respiratory tract infection in New Delhi: Qualitative study

\author{
Anita Kotwani, P. C. Joshi' ${ }^{1}$, Urmila Jhamb ${ }^{2}$, Kathleen Holloway ${ }^{3,4}$
}

\begin{abstract}
:
OBJECTIVE: The objective of the study was to explore the prescribing practices, knowledge, and attitudes of primary care doctors and community pharmacists, regarding antibiotic use in acute upper respiratory tract infections (URTI) and diarrhea in children to better understand causes of misuse and identify provider suggestions to change such behavior.

MATERIALS AND METHODS: Two focus group discussions (FGDs) each were conducted with primary care government doctors (GDs), private general practitioners (GPs), pediatricians, and community pharmacists in Delhi. Each FGD had 8-12 participants and lasted $2 \mathrm{~h}$. Furthermore, 22 individual face-to-face semi-structured interviews were conducted with providers of varying type and experience at their workplaces. Thematic and summative qualitative content analysis was done.

RESULTS: All groups admitted to overusing antibiotics, GPs appearing to use more antibiotics than GDs and pediatricians for URTI and diarrhea in children. Pharmacists copy the prescribing of neighborhood doctors. Antimicrobial resistance (AMR) knowledge was poor for all stakeholders except pediatricians. Causes for prescribing antibiotics were patient pressure, profit motive, lack of follow-up and in addition for GDs, workload, no diagnostic facility, and pressure to use near-expiry medicines. Knowledge was gained through self-experience, copying others, information from pharmaceutical companies, and for some, training, continuous medical education/conferences. All groups blamed other professional groups/quacks for antibiotic overuse. Interventions suggested were sensitizing and empowering prescribers through training of providers and the public about the appropriate antibiotic use and AMR and implementing stricter regulations.
\end{abstract}

CONCLUSIONS: A package of interventions targeting providers and consumers is urgently needed for awareness and change in behavior to reduce inappropriate community antibiotic use.

Keywords:

Antibiotic use, antimicrobial resistance, behavior and perception, focus group discussion, qualitative study, rational antibiotic use

\section{Introduction}

Tnappropriate antibiotic consumption Iis a major contributor to antimicrobial resistance (AMR) in the community. Acute upper respiratory tract infections (URTIs) and acute uncomplicated diarrhea are two

This is an open access article distributed under the terms of the Creative Commons Attribution-NonCommercial-ShareAlike 4.0 License, which allows others to remix, tweak, and build upon the work non-commercially, as long as the author is credited and the new creations are licensed under the identical terms.

For reprints contact: reprints@medknow.com common illnesses that generally do not require antibiotic therapy though antibiotics are commonly prescribed. ${ }^{[1]}$ In India, studies have revealed up to $53 \%$ of patients in primary care in the public sector and about $70 \%$ of patients in the private sector receive antibiotics for URTI and acute diarrhea. ${ }^{[2-4]}$

How to cite this article: Kotwani A, Joshi PC, Jhamb U, Holloway K. Prescriber and dispenser perceptions about antibiotic use in acute uncomplicated childhood diarrhea and upper respiratory tract infection in New Delhi: Qualitative study. Indian J Pharmacol 2017;49:419-31. 
Prudent antibiotic use, as well as adequate knowledge and awareness about AMR, is needed to contain AMR and this was clearly mentioned in the 2001 World Health Organization (WHO) Global Strategy on $\mathrm{AMR}^{[5]}$ and now clearly stated in the Global Action Plan (GAP) on AMR (2015) prepared by the World Health Organization. ${ }^{[6]}$ To develop effective strategies to change prescriber behavior, qualitative research into their beliefs, motivations, and practices is needed. ${ }^{[7]}$ For qualitative research, focus group discussions (FGDs) were used as this method provides richer and concentrated data on complex behavior. ${ }^{[8]}$ In this study, FGDs and interviews were conducted with doctors (community doctors and pediatricians) and dispensers (community pharmacists and informal dispensers) to understand the (i) treatment practices for acute diarrhea and URTIs in children; (ii) knowledge and attitudes concerning antibiotic resistance; (iii) attitude and behavior regarding antibiotic use; (iv) opinions on strategies to reduce antibiotic prescribing for acute diarrhea and acute uncomplicated URTIs.

\section{Materials and Methods}

FGDs and semi-structured interviews were conducted for primary care government doctors (GDs) working under Delhi Government, private general practitioners (GPs), pediatricians of the Delhi government sector and private sector, qualified community pharmacists $(\mathrm{PH})$, and informal/hired dispensers (IP). Pediatricians were included as they see many children with URTI and diarrhea, unlike other specialists.

A topic guide was prepared [Annexure 1, Supplement Data] which had certain preidentified themes, based on which the FGD probe questions were asked. The study was approved by the Institute Ethics Committee of the first author. Written consent was obtained from all the participants. The FGDs were conducted during September-December 2014.

Eight FGDs were conducted, two from each of four professional groups: GPs, GDs, pediatricians, and pharmacists. The permission was obtained from Directorate Health Services (DHS) office, Government of National Capital Territory (NCT) of Delhi to request all the Zonal-in-Charge of ten districts of NCT, Delhi, for deputing a medical officer from their respective districts for the FGDs. President, Indian Academy of Paediatrics and President, Pharma Solution (pharmacists) confirmed cooperation for FGDs with their respective peer groups. General Secretary, Indian Medical Association Delhi Branch facilitated cooperation of Zonal office bearers. The participants were nominated by their respective professional organizations. Authorities and organizations were able to provide us a representative sample by nominating the participants from each district and different regions of Delhi.

Each FGD consisted of 8-12 participants and elicited detailed information on their stated prescribing patterns for acute diarrhea and URTI in children, views on AMR, and practical interventions for promoting the rational use of antibiotics. Anonymity of all participants was maintained by the use of group abbreviation and serial number. All FGDs were interactive discussions. We ensured that each FGD had participants from all the districts of NCT Delhi. The detailed characteristics of participants are mentioned in Table 1. Each FGD lasted for about $120 \mathrm{~min}$ and was conducted and moderated by a team of three members - behavioral/social scientist, pharmacologist, and a pediatrician. The social scientist is a professor of social anthropology, and an expert on qualitative research in health and the pharmacologist is a professor of pharmacology who has done many antibiotic use and behavior studies. A pediatrician was included to have a prescribing clinician involved in moderation of the FGDs and to give feedback to the participants at the end of each FGD on what treatment guidelines recommended for the treatment of acute respiratory tract infection and diarrhea. This was felt to be ethically necessary. All FGDs were audio and videotaped. All the participants were informed, and it was mentioned in the consent form that confidentiality will be strictly maintained. After the initial $10 \mathrm{~min}$ of interaction with the expert facilitators and in the group, all the participants were comfortable in sharing their views.

The data generated were supplemented by face-to-face semi-structured interviews with additional participants from different stakeholder groups who were contacted and interviewed at the place of their practice (dispensary/clinic or retail pharmacy shop). The participants for the face-to-face interviews were selected by convenience from those zones of Delhi from where representation was comparatively poor and to cover the entire range of experience of each group [Table 1]. For informal dispensers (sale persons in pharmacy shops), there is no association so only interviews (no FGDs) were held to include their views as this group is involved in dispensing and to an extent in prescribing. Twenty-two interviews (four with GDs, five with GPs, two with pediatricians [government and private], six with community pharmacists, and five with informal dispensers) were conducted. The individual interviews lasted for about $1 \mathrm{~h}$ and were conducted by the first author. All interviews were audiotaped.

After transcribing and translating all the recorded FGDs and interviews, data analysis was done using 
Table 1: Characteristics of participants for focus group discussion and interviews

\begin{tabular}{|c|c|c|c|c|}
\hline Group (qualification) & $\begin{array}{c}\text { Total } \\
\text { number }\end{array}$ & $\begin{array}{l}\text { Male and } \\
\text { female }\end{array}$ & $\begin{array}{l}\text { Year of experience } \\
\text { in years }\end{array}$ & Nominated \\
\hline \multicolumn{5}{|c|}{ Focus group discussion } \\
\hline GDs (MBBS) & 19 & 9 and 10 & $1-18$ & $\begin{array}{l}\text { Directorate Health Services, GNCT, Delhi and from } \\
\text { all the zones by their Zonal-In charge }\end{array}$ \\
\hline Private practitioners, GPs (MBBS) & 17 & 16 and 1 & $1-40$ & $\begin{array}{l}\text { North, South, East and West Delhi Branch of Indian } \\
\text { Medical Association }\end{array}$ \\
\hline Pediatricians (MD) & 21 & 17 and 4 & $5-48$ & Indian Academy of Pediatrics - Delhi Branch \\
\hline $\begin{array}{l}\text { Community pharmacists (diploma in } \\
\text { pharmacy/bachelor of pharmacy) }\end{array}$ & 20 & 20 male & $3-43$ & $\begin{array}{l}\text { Pharma Solution (NGO with community pharmacists } \\
\text { as members) }\end{array}$ \\
\hline \multicolumn{5}{|c|}{ Face-to-face interview } \\
\hline GDs (MBBS) & 4 & 4 female & $9-20$ & $\begin{array}{l}\text { One each from North, South, East, and West Delhi. } \\
\text { Permission from respective Zonal-in charge }\end{array}$ \\
\hline Private practitioners, GPs (MBBS) & 5 & 2 and 3 & $13-30$ & South and East Delhi. Reference and personal liaison \\
\hline Pediatricians (MD) & 2 & 1 and 1 & 8 and 15 & East and South Delhi (Delhi Government) \\
\hline $\begin{array}{l}\text { Community pharmacists (diploma in } \\
\text { pharmacy) }\end{array}$ & 6 & 6 male & $10-20$ & $\begin{array}{l}\text { East and South Delhi } \\
\text { Reference and personal liaison }\end{array}$ \\
\hline $\begin{array}{l}\text { Informal dispensers (no formal } \\
\text { qualification in pharmacy) }\end{array}$ & 5 & 5 male & $5-24$ & $\begin{array}{l}\text { North, South, East, and West Delhi } \\
\text { Reference and personal liaison }\end{array}$ \\
\hline
\end{tabular}

GPs=General practitioners, NGO=Nongovernmental organization, GDs=Government doctors

thematic and summative qualitative content analysis. ${ }^{[9]}$ A two-stage analysis was applied by two researchers who read all the transcripts independently and repeatedly. First coding of the data was done by both the researchers and then they compared their open codes until consensus was reached. This was followed by axial coding to check for consistency; the keywords, themes, and subthemes were likewise identified and compared.

\section{Results}

Four major themes, each with further sub-themes emerged on data analysis of FGDs and face-to-face interviews.

\section{Antibiotic prescribing trends}

Prescribing pattern for acute upper respiratory tract infection

Most GDs and pediatricians stated that they initially start symptomatic treatment and restrict the use of antibiotics, unlike private GPs. Dispensers' copied doctors' prescribing:

"I do not give antibiotics at all even if the patient is insisting... nasal drops, decongestants, cough syrups or may be PCM (paracetamol) in case of fever are enough (Private Pediatrician (P. Ped2)."

"Usually when a patient goes to a GP he expects that he will be alright in one or two days' time Doctor does not have any option, he usually has to give antibiotic for fast recovery of the patient (GP4)."

Details for treatment by various stakeholders are mentioned in Table 2.
Prescribing pattern for acute diarrhea

Most GD and pediatricians were markedly against prescribing any antibiotic, relying solely on zinc and ORS therapy, unlike many private GPs who viewed antibiotics as a first-line treatment for diarrhea, often prescribing a fixed-dose combination of ofloxacin + ornidazole. Pharmacists including informal dispensers copied doctors' prescribing as they did for URTI treatment.

"We give medicine like ORS and zinc for 14 days... as the supply is from NRHM (National Rural Health Mission) stock and we follow guidelines (GD6)."

"I do give ORS and rarely Zinc. I prescribe oflox + ornidazole (GP5)."

"I dispense oflox and ornidazole usually. This is the usual combination that is prescribed by doctors. Apart from this, ORS and Zinc is also sometimes given (Pharmacists (PH 2)."

One GP was prepared to give inpatient treatment in his clinic. "If a child does not respond (to usual antibiotics) in 2-3 days then I admit the patient and give vancomycin intravenously (GP8)."

Details for treatment by various stakeholders are mentioned in Table 3.

\section{Knowledge and attitudes concerning antibiotic} resistance and newer antibiotics

Most pediatricians were highly aware of the hazards of antibiotic misuse and that not many new antibiotics are being developed while GPs were not. While many GDs agreed that AMR was a problem in the community, about one-third did not feel the need to press panic 
Table 2: Prescribing patterns for acute upper respiratory tract infections in children in the community as mentioned by focus group discussion participants and interviewees

\begin{tabular}{|c|c|}
\hline Stakeholder & Prescribing pattern \\
\hline \multirow[t]{2}{*}{$\begin{array}{l}\text { GDs - public } \\
\text { sector }\end{array}$} & $\begin{array}{l}\text { Usually symptomatic treatment for URTI in children } \\
\text { for three days - anti-histaminic syrup, steam } \\
\text { inhalation, and paracetamol and sometimes, nasal } \\
\text { decongestant or cough syrup }\end{array}$ \\
\hline & $\begin{array}{l}\text { If patients return and the condition is not improved } \\
\text { they generally add antibiotic, amoxicillin, } \\
\text { co-trimoxazole, cephalexin - in syrup form if available }\end{array}$ \\
\hline Pediatricians & $\begin{array}{l}\text { Usually prescribe symptomatic treatment but may } \\
\text { sometimes prescribe antibiotics such as cephalexin }\end{array}$ \\
\hline \multirow[t]{2}{*}{$\begin{array}{l}\text { GPs - private } \\
\text { sector }\end{array}$} & $\begin{array}{l}\text { Generally, prescribe antibiotics, including newer } \\
\text { ones - azithromycin, co-trimoxazole (septran), } \\
\text { amoxicillin, cephalexin, roxithromycin, cefpodoxime } \\
\text { syrup, and cefixime }\end{array}$ \\
\hline & $\begin{array}{l}\text { Mentioned patients come after } 2-3 \text { days of } \\
\text { symptoms having taken some medicines at home } \\
\text { maybe on the advice of pharmacists or drug sellers, } \\
\text { so it is not known whether patients have already } \\
\text { consumed antibiotics }\end{array}$ \\
\hline \multirow[t]{3}{*}{$\begin{array}{l}\text { Community } \\
\text { pharmacists }\end{array}$} & $\begin{array}{l}\text { For patients without prescription, pharmacists usually } \\
\text { give an antiallergic, nasal decongestant, or cough } \\
\text { syrup and sometimes an antibiotic }\end{array}$ \\
\hline & $\begin{array}{l}\text { The usual antibiotics prescribed and dispensed are } \\
\text { - augmentin (amoxicillin+clavulanic acid) cefixime, } \\
\text { azithromycin and co-trimoxazole as these are the } \\
\text { antibiotics generally prescribed by private GPs }\end{array}$ \\
\hline & $\begin{array}{l}\text { Generally copied the prescribing pattern of local } \\
\text { doctors }\end{array}$ \\
\hline
\end{tabular}

The patterns of prescription mentioned in the tables are a summary of what was we can substitute mentioned during the FGDs and semi-structured interviews conducted. GPs=General practitioners, URTI=Upper respiratory tract infections, FGDs=Focus group discussions, GD = Government Doctors

Table 3: Prescribing pattern by various stakeholders for acute diarrhea in children in the community as mentioned by focus group discussion participants and interviewees

\begin{tabular}{ll}
\hline Stakeholder & Prescribing pattern \\
\hline GDs - public sector & Generally, rely solely on zinc and ORS, \\
& being aware of treatment guidelines for \\
& management of acute diarrhea in children \\
& and these medications are always in stock \\
& for dispensing but sometimes also give \\
& metronidazole and norfloxacin
\end{tabular}

Pediatricians Generally, prescribe zinc with ORS and other symptomatic therapy, but few prescribe antibiotics, usually ofloxacin + ornidazole, may be due to parent pressure

GPs - private sector Usually prescribe an antibiotic along with ORS and or probiotic and lactobacillus preparations

Usual antibiotic is ofloxacin + ornidazole in fixed-dose combination

Were not generally aware of zinc therapy for diarrhea

Community pharmacists Generally copied the prescribing patterns of GPs

The patterns of prescription mentioned in the tables are a summary of what was mentioned for each stakeholder during the FGDs and semi-structured interviews conducted. FGDs=Focus group discussions, GPs=General practitioners, GDs=Government doctors, ORS = Oral Rehydration Solution button yet as they still were getting good results with antibiotics. "I think AMR is more related to hospital acquired resistance and not due to dispensaries (GD10)." "If I give 10 people with amoxicillin, we get good results. I have not seen that they are resistant with usually prescribed antibiotics (GD5)." Probing revealed that the main condition for prescribing antibiotics was URTIs even though doctors knew that URTIs are usually viral in origin, not needing antibiotics. Some GDs complained that newer antibiotics were not supplied to their dispensaries (primary care). Further probing revealed that many GDs and GPs assumed that newer combinations or variants of the same class were "newer antibiotics." "Many new antibiotics are available on pharmacy shops which contain two good antibiotics and are usually prescribed by private doctors (GD7)."

GPs mostly denied the severity of AMR in the community calling it manageable with newer antibiotics. Most GPs believed that newer antibiotics are still being developed.

Most pharmacists were unconcerned about AMR. "I don't think (AMR) to be such a bad situation. Antibiotics are necessary for quick treatment (PH 4)." The hired salespersons (informal dispenser [IP]) at the shops were grossly unaware and unconcerned. "If doctors prescribe an antibiotic then it's definitely required and $A M R(?)$ is not such a big problem (IP3)."

Attitude and behavior concerning antibiotic use Three subthemes underlying antibiotic misuse were identified:

i. Major causes for prescribing and antibiotic misuse included: patient pressure, lack of follow up, self-medication, and not losing patients or for profits. Public sector doctors also mentioned huge workload, prevailing culture, no diagnostic facility, and pressure to use short-dated medicines. Details are mentioned in Box 1.

a. Patient pressure: All prescribers and dispensers cited patient demands for antibiotics as the major reason for prescribing antibiotics for diarrhea and URTI.

b. Lack of follow-up: All prescribers and dispensers stressed that patients seldom comply with a doctor's insistence on follow-up, especially if they feel better after a few doses.

c. Self-medication: Self-medication through reliance on old antibiotic prescriptions or through consulting family or friends is a major cause of antibiotic misuse.

Pharmacists are a major role player in self-medication. Patients prefer buying antibiotics directly from pharmacy shops to avoid long waiting periods and/or high consultation fees of doctors. Information may be gained from 
Box 1: Sub-theme - causes for prescribing and misuse of antibiotics

\section{Patient pressure}

GDs mentioned demands from poorer slum based patients for "powder based medicine", a reference made by them for antibiotic syrup for children (GD13)".

Pediatricians are faced with very demanding parents of sick children. "In cases of (acute) diarrhea, the parent gets worried if they see the child passing stools after every few minutes and they come to us with the demand of quickly treating their child (private pediatrician 3)." Some pediatricians yield to these demands to retain the patient.

Pharmacists and GPs strongly believed patient demand/ expect something more than a common pill. "The attitude of negligence to buy antibiotics on prescription and the demands by patients for antibiotics especially without a prescription is abundant (pharmacist PH 18)".

\section{Lack of follow-ups}

"The only time a patient comes for a follow-up is when(s) he is getting worse, or not feeling better, then we have to change the antibiotic (GD15)".

"They (patients) do not come if they feel the medicine is working fine. They stop taking the medicine half way through if they find it effective (GP4)".

Self-medication

Doctors routinely encounter patients who "either buy the same antibiotics on getting similar symptoms again or recommend/pass on the antibiotics they took at the time of their illness, to friends or relatives with similar symptoms (GP7)." "After that if they approach us ... we put them on a higher line of antibiotics, we do not have other option (GP1)".

Pharmacists play a major role in self-medication as dispensing of the antibiotics over-the-counter, or based on expired prescriptions, are common in every part of the country.

\section{Profit motive}

Most GPs and pharmacists cited profit motives and competition to secure more patients/customers. "A doctor is most of all worried about losing a patient (GP9)." In such a scenario, antibiotics are also prescribed to justify the relatively high consultation fees charged by the GPs.

Community pharmacist, "If I do not dispense antibiotic, it does not mean that the next shop or pharmacist will not, someone will, and from the next time patient will go there instead of my shop. Losing a patient is thus, equivalent to losing a customer (PH 13)".

\section{Public sector doctors}

Workload: Huge number of patients and no time for counseling. Culture: "I cannot discuss for too long with one patient, others in the line create chaos, and especially in case of a female patient or mother of a child, people start asking what am I talking to a female for so long as my dispensary is in a village (government pediatrician 1)".

Lab diagnostic tests: "Due to lack of lab facilities tests for the patients in the facility it is difficult to diagnose the nature of infection whether it is bacterial or viral. In order to not take the risk, patient is thus, given an antibiotic (GD14)".

Drug supply: "Medicine supply is erratic and irregular. There are instances when a certain drug is not in supply for many months while sometimes there will be an oversupply. Authorities put constant pressure on doctors to prescribe the drugs if they are abundant in supply and to exhaust them before their expiry date (GD3)".

GDs=Government doctors, GPs=General practitioners

the internet and there is a lack of awareness of antibiotic misuse. d. Profit motives: Most GPs cited profit motives and competition to secure more patients/customers. Community pharmacists were also influenced by the motive to earn profit [Box 1]

e. Additional reasons for public sector doctors: Public sector doctors mentioned a few reasons which were specific to their workplace:

- High workload

- Prevailing culture

- Absence of laboratory diagnostic tests

- Erratic drug supply.

ii. Source of information and knowledge: Doctors and dispensers gained their knowledge through self-experience, copying others, information from pharmaceutical companies, and for some, induction training, Continuous Medical Education (CMEs), and conferences [Box 2].

a. Experience on the job: Prescribing based on self-experience was frequently followed.

b. Medical representatives of drug companies: Both GPs and pharmacists mentioned learning from representatives of pharmaceutical company.

c. Following trends of GPs and other doctors: All community pharmacists mentioned picking up prescription patterns of doctors based in their vicinity.

d. Induction trainings, CMEs, and conferences: Most doctors expressed their dissatisfaction with CMEs and conferences. GDs appreciated the training on guidelines for treatment of diarrhea which was conducted by their employer, the DHS.

iii. Blame game: all stakeholders blamed other professional groups or quacks/paramedical staff practicing illegally for the problem of AMR [Box 3]. a. Blaming inappropriate access to antibiotics of paramedical staff, workers at pharmacy stores: All health personnel unanimously raised the issue of quacks or junior staff in hospital/clinics as major source of antibiotic dispensing to people.

b. Blaming each other for misuse of antibiotics: Some public sector doctors blamed GPs as channels of rampant circulation of antibiotics in community.

GPs attributed over the counter (OTC) dispensing of antibiotics by pharmacists as the major channel of easy access to antibiotics.

Pharmacists blamed the doctors for irresponsible prescription of antibiotics which lead people to demand those antibiotics.

Strategies for interventions to reduce antibiotic prescribing for acute diarrhea and acute upper respiratory tract infection

Three types of practical intervention were suggested: 
Box 2: Subtheme - source of information and knowledge for treatment

\section{Experience on the job \\ "Doctors learn over a period of time about what to prescribe in what cases and they gather expertise with time. (GP8)." \\ Pharmacists echoed the same. \\ Medical representatives of pharmaceutical companies \\ Both GPs and pharmacists learn from representatives of pharmaceutical companies. "Incentives popularize a certain drug, and that depends on how a representative has marketed them to the doctors and pharmacist (PH 9)". \\ Following trends by GPs and other doctors}

Community pharmacists picked up prescription patterns of local doctors.

\section{Induction training, CMEs and conferences}

Most doctors expressed dissatisfaction with CMEs and conferences. "Any regular CME will never be about diarrhea or anything (similar), they only focus on "high end" diseases like cardiac, orthopedic, etc., as these CMEs are generally sponsored by pharmaceutical companies (GP5)".

GDs appreciated the training on guidelines for treatment of diarrhea given by the Directorate Health Services to all the in-charges of primary health care (dispensaries) who were then asked to train the medical officer under them. Simultaneously the drug supply for treatment of diarrhea - both ORS and zinc tablets are being supplied in abundance through NRHM. This dual approach helped the doctors implement the guidelines.

NRHM=National Rural Health Mission, GPs=General practitioners, CMEs=Continuous Medical Educations, GDs=Government doctors, ORS= Oral Rehydration Solution

\section{Box 3: Sub-theme - blame game}

\section{Paramedical staff, quacks, and workers at pharmacy stores}

All health personnel raised the issue of quacks or junior paramedical staff in hospital/clinics as major sources of antibiotic dispensing to people. Such practitioners learn from the prescribing patterns of doctors in cities and practice in their native villages or in slum areas of cities.

"In many areas, these paramedical staff start their own practice and dispense medicines including antibiotics (GD6)".

"Most of these are self-dispensing since they themselves do not know the exact names of most of the antibiotics. They can hardly spell the antibiotics correctly (GD3)".

\section{Blaming each other for misuse of antibiotics}

Some public-sector doctors and pediatricians blamed GPs for misusing antibiotics "The private doctors do not start treatment without antibiotics" (PPed 8).

GPs blamed pharmacists for over-the-counter dispensing of antibiotics.

Pharmacists blamed doctors for irresponsible prescription of antibiotics which leads people demanding those antibiotics. "pharmacists prescribe medicines only after a certain trend is followed by a doctor in an area" (PH 9).

GPs=General practitioners, GD=Government doctor

i. Sensitizing and empowering the doctors/medical staff through the provision of independent information, treatment guidelines, undergraduate training, and CME on common conditions including acute diarrhea and URTI by employers and associations.

ii. Creating public awareness regarding the rational use of antibiotics through national campaigns, using visual and print media and various channels including pharmacy shops.

iii. Implementing stricter regulations regarding antibiotic prescription and usage, not only applicable for OTC sales in pharmacies but also for the supply of relevant antibiotics to public primary care and stricter rules for pharmaceutical companies to approach GPs and pharmacy shops. Both doctors and pharmacists suggested that there should be a government unit dedicated to promoting rational use of antibiotics.

Details are mentioned in the Box 4.

\section{Discussion}

This study shows that prescribers and dispensers admitted to much misuse of antibiotics for acute URTI and diarrhea, especially in private sector, which is consistent with findings from other studies. ${ }^{[4,10]}$ Despite knowing that URTI is often viral, not needing antibiotics, and despite guidelines against the use of antibiotics for URTIs, all the doctors including pediatricians reported administering antibiotics in cases of URTIs. Recent surveys $^{[11,12]}$ conducted in India have demonstrated findings similar to those of our study, for example, a survey conducted by the WHO in September-October 2015 showed high and inappropriate antibiotic use for acute URTI and diarrhea. ${ }^{[12]}$ In the present study, we found combination of antibiotics (ofloxacin + ornidazole) for diarrhea was commonly used by GPs and community dispensers who also thought that most antibiotic combination products constituted new antibiotics. Community dispensers copied the prescribing of neighborhood GPs, and this is a major concern as private pharmacy outlets are popular and the initial source of treatment in most low-middle-income countries including India ${ }^{[10]}$ It may be that rational prescribing by doctors would lead to less misuse of antibiotics at private retail pharmacies. Therefore, policymakers must take all steps to "educate"' doctors about the optimum use of antibiotics which may automatically have an impact on the prescribing and dispensing habits of pharmacists and informal dispensers.

Patient pressure as found in this study has often been reported elsewhere. ${ }^{[13]}$ It is possible that prescriber perception of patient pressure is greater than actual pressure. ${ }^{[14]}$ In this study, prescribers were convinced that it was patients who asked for strong medicines, though in a previous study from New Delhi, doctors agreed that most patients wanted "strong medicine" for quicker symptomatic relief but were not aware of antibiotics. ${ }^{[15]}$ Therefore, one of the interventions could be public awareness on antibiotic and appropriate use of antibiotics as clearly mentioned for GAP on AMR by the WHO. ${ }^{[6]}$ 
Box 4: Strategies suggested by the stakeholders to improve antibiotic prescribing for acute diarrhoea and acute upper respiratory tract infection in the community

Sensitizing and empowering the doctors and health staff
Crisp and up-to-date sources of information on appropriate
antibiotic use by employer and medical associations.
Inclusion of the treatments for acute URTI and diarrhea in
treatment guidelines and CMEs.
Mandatory induction training for all medical officers covering topics
like AMR and treatment guidelines for common ailments and also
during in-service training.
Rational use of antibiotics, treatment guidelines for common
ailments and AMR to be included during undergraduate medical
and pharmacy courses.
Practical training in AMR and consequences of resistance should
be stressed in hospital ward teaching to medical students.
Auxiliary Nurse Midwifery to counsel patients about home
remedies for diarrhea and URTI, making ORS solutions and
stressing for no need for antibiotics.

Creating awareness regarding rational use of antibiotics among public

Both doctors and pharmacists highlighted the need for awareness about AMR and rational use of antibiotics for general public.

Suggestions involved spreading awareness through print and visual media, health campaigns through catchy slogans on radio and televisions involving celebrities.

Every pharmacy shop to have posters warning patients about misuse of antibiotics, to complete the course of antibiotics, and differentiating antibiotics from OTC drugs.

Stricter regulations regarding antibiotic prescription and usage

Doctors stressed the need to check OTC sales as well as the practice of self-medication and holding pharmacists and quacks to account.

Doctors and pharmacist group suggested that pharmacists could put a stamp after dispensing antibiotics on the prescription,

"antibiotic dispensed and no refill"

Pharmacists mentioned it should be mandatory for doctors to write indication or reasons for prescribing antibiotics to patient on the prescription.

GDs stated that there should be regular supply of antibiotics on the essential medicines list to government primary care dispensaries.

Both doctors and pharmacists pressed the need for a "rational antibiotics use cell' within the Ministry of Health to regulate and monitor usage of antibiotics.

Pharmaceutical companies should be regulated in approaching primary care doctors and pharmacists regarding newer antibiotics. CMEs=Continuous Medical Educations, URTI=Upper respiratory tract infection, AMR=Antimicrobial resistance, OTC=Over-the-counter, GDs=Government doctors, ORS $=$ Oral Rehydration Solution

Some studies have shown that doctors perceive it easier to prescribe antibiotics than to refrain from giving them and that they believe AMR is a problem but less relevant to their own practice. ${ }^{[16,17]}$ However, in Sweden patients reported higher confidence in physicians who had given information to them, whether or not they prescribed antibiotics. ${ }^{[18]}$ A study conducted in Nepal ${ }^{[19]}$ has shown that patients' demands did not influence prescribing behavior and patients were happy to accept advice from prescribers, even if that meant taking fewer drugs. A study conducted with high school teachers and students in New Delhi ${ }^{[20]}$ revealed that patients are not encouraged to ask questions, nor is counseling done by doctors so indicating less actual patient demand and more perception of demand for antibiotics by doctors. Public awareness programs on the appropriate use of antibiotics as suggested by various groups in this study will not only be useful for patients not to demand antibiotics but also ease the perceptions by doctors for demand of antibiotics.

Blaming patients or other practitioners is an interesting finding found in this study though has also been reported. Doctors have been found blaming patients, ${ }^{[21]}$ public sector doctors blaming private sector doctors, ${ }^{[22]}$ and doctors blaming pharmacists for dispensing antibiotics inappropriately without prescription. ${ }^{[15]}$ Community pharmacists, in turn, have stated that they pick up prescribing knowledge from doctors. ${ }^{[23]}$

The poor awareness of community doctors about AMR, their feeling that AMR was not a problem, and their false belief that combination products represented new antibiotics is worrying and needs urgent attention by the policymakers and regulators. Even where some doctors admitted to the fact that AMR may cause some resistant urinary tract infection cases, many doctors did not seem to realize that AMR may make surgery and cancer chemotherapy impossible. Other studies have also shown that doctors consistently denied resistance in their wards and did not suggest any measures to change their faulty prescription behavior. ${ }^{[17,24]}$

In this study, most GDs wanted regular weekly literature on issues such as AMR, but at the same time, many GDs mentioned not having enough time to participate in CME or read literature due to being overburdened with patients and administrative work. While GPs advocated stricter policies, they themselves were unaware of newer regulations under the new $\mathrm{H} 1$ schedule for restricting the sale of antibiotics. ${ }^{[25]}$ The Government of India has introduced $\mathrm{H} 1$ schedule $^{[26]}$ for restricting the OTC sale of antibiotics as per Antibiotic Policy (MHFW 2011). Under schedule H1, all third-generation and newer antibiotics are listed, for these antibiotics' prescription is mandatory and pharmacists are supposed to keep a record of the sale. However, ground-oriented steps have not yet been taken to check OTC sales. Many pharmacists agreed during the FGDs that they honor old prescriptions brought by patients and dispense antibiotics without prescription which indicates that, in reality, very few pharmacists actually complied with the $\mathrm{H} 1$ rule for dispensing antibiotics under schedule H1. The policy, though formulated, has not been publicized much. A recent study (2016) has reported high sales of OTC antibiotics (including carbapenems) in spite of federal regulation of schedule $\mathrm{H} 1 ;^{[27]}$ the authors of that 
study concluded that behavior change among doctors and patients should be prioritized.

Interestingly, both doctors and pharmacists suggested establishing a "Rational Antibiotics Use Cell" within the Ministry of Health, to coordinate the implementation of a package of policies. The suggestion to implement a package of policies targeting providers and the public mirrors actual experience found elsewhere. ${ }^{[28]}$ Such a policy package would include strict monitoring of OTC antibiotic sales, surveillance of antibiotic use, and inclusion of AMR and rational use of antibiotics in medical, nursing, dental, and pharmacy curriculum and relevant training at undergraduate level and in CME as mentioned in $\mathrm{GAP}^{[6]}$ and recently National Action Plan (NAP) on AMR developed by Government of India. ${ }^{[29]}$ Attention should also be given to the government supply system since it was mentioned that there was pressure to use the near expiry antibiotics (whether or not it was appropriate) and that newer antibiotics were supplied to dispensaries (primary care) despite not being in the essential medicine list for dispensaries, as reported previously. ${ }^{[30]}$ Such supply of second- and third-generation antibiotics to primary care should be curtailed.

\section{Limitations}

One main limitation of the study was that only four to six GDs, community pharmacists, and GPs from North, South, East, and West Delhi were involved in FGDs and thus may not be representative of general practice as a whole. However, in addition to FGDs, we also did in-depth interviews with various stakeholders included in the study with special care to get representation from all districts, gender, and age. Common themes did emerge from the FGDs and thematic saturation was satisfactorily achieved; yet caution should be taken in generalizing the findings. Another limitation could be that attitude, knowledge, and belief of doctors and pharmacists have changed since the study was conducted in September-December 2014. However, attitudinal and behavioral changes typically occur over a long time, requiring sustained outreach and interventions. India is planning such interventions under activities for NAP on AMR. A further limitation is that the behaviors reported in this paper may not actually reflect what prescribing and dispensing is actually done by the FGD participants and interviewees. Nevertheless, this study is the kind of study that supplies the data needed to develop targeted outreach and strategic interventions.

\section{Strengths}

This study is probably the first in-depth qualitative study in India trying to explore the antibiotic prescribing practices for acute diarrhea and for URTI in children and knowledge and attitude regarding AMR by various prescribers in the community including community pharmacists. The findings have important implications as one of the main strengths of this study was the participation of both public and private sector doctors including pediatricians and community pharmacists including informal dispensers.

\section{Conclusions}

The study highlights the inappropriate use of antibiotics for acute URTI and diarrhea, together with a lack of awareness about AMR, by doctors and dispensers. None of the providers viewed themselves as part of AMR problem, blaming others, including consumers. Interventions suggested for decreasing use were often aimed at others, not themselves. There is an urgent need to (1) increase the awareness about misuse of antibiotics in acute diarrhea and URTI and how it contributes to AMR through training of both providers and the public on appropriate antibiotic use and AMR, (2) implement a package of policies (including managerial interventions such as supplying appropriate antibiotics and enforcing regulations) to encourage all stakeholders to use antibiotics appropriately, and (3) regularly monitor antibiotic use in the community to evaluate policy effectiveness and inform further actions to improve the rational use of antibiotics. Current political commitments in the country can contribute to an enabling environment for actions. Government of India has developed the NAP on AMR which is aligned with the GAP of WHO and is committed to combat AMR, ${ }^{[29]}$ soon activities as per NAP will be started and the findings of the present study will be useful for many activities.

\section{Acknowledgments}

The work was funded the WHO, South East Asia Regional Office, New Delhi. Mr. Tapan Behl and Ms. Zeba helped in organizing the FGDs and video and audio recording of FGDs and face-to-face interviews.

\section{Financial support and sponsorship}

Nil.

\section{Conflicts of interest}

There are no conflicts of interest.

\section{References}

1. van den Broek d'Obrenan J, Verheij TJ, Numans ME, van der Velden AW. Antibiotic use in Dutch primary care: Relation between diagnosis, consultation and treatment. J Antimicrob Chemother 2014;69:1701-7.

2. Kotwani A, Chaudhury RR, Holloway K. Antibiotic-prescribing practices of primary care prescribers for acute Diarrhea in New Delhi, India. Value Health 2012;15:S116-9.

3. Kotwani A, Holloway K. Antibiotic prescribing practice for acute, uncomplicated respiratory tract infections in primary care settings 
in New Delhi, India. Trop Med Int Health 2014;19:761-8.

4. Pathak D, Pathak A, Marrone G, Diwan V, Lundborg CS. Adherence to treatment guidelines for acute diarrhoea in children up to 12 years in Ujjain, India - A cross-sectional prescription analysis. BMC Infect Dis 2011;11:32.

5. World Health Organization. WHO Global Strategy for Containment of Antimicrobial Resistance; 2001. Available from: http//www.whoint/drugresistance/WHO_Global_Strategy_ Englishpdf. [Last accessed on on 2017 Aug 8].

6. World Health Organization. Global Action Plan on Antimicrobial Resistance. Geneva: WHO; 2015. Available from:http://www. who.int/drugresistance/global_action_plan/en/. [Last accessed on on 2017 Aug 8].

7. Ashiru-Oredope D, Hopkins S. Antimicrobial resistance: Moving from professional engagement to public action. J Antimicrob Chemother 2015;70:2927-30.

8. Marshall C, Rossman GB. Designing Qualitative Research. Thousand Oaks: Sage Publications; 2006.

9. Hsieh HF, Shannon SE. Three approaches to qualitative content analysis. Qual Health Res 2005;15:1277-88.

10. Holloway KA, Ivanovska V, Wagner AK, Vialle-Valentin C, Ross-Degnan D. Have we improved use of medicines in developing and transitional countries and do we know how to? Two decades of evidence. Trop Med Int Health 2013;18:656-64.

11. Maheshwari P, Praveen D, Ravichandiran V. A study on patients awareness on rational use of antibiotics and its resistance. Asian J Pharm Clin Res 2015;8:204-6.

12. World Health Organization. Antibiotic Resistance: Multi-Country Public Awareness Survey: Geneva: WHO; 2015. Available from: http://www.apps.who.int/iris/ bitstream/10665/194460/1/9789241509817_eng.pdf. [Last accessed on on 2017 Aug 8].

13. Stivers T, Mangione-Smith R, Elliott MN, McDonald L, Heritage J. Why do physicians think parents expect antibiotics? What parents report vs. what physicians believe. J Fam Pract 2003;52:140-8.

14. Little P, Dorward M, Warner G, Stephens K, Senior J, Moore M, et al. Importance of patient pressure and perceived pressure and perceived medical need for investigations, referral, and prescribing in primary care: Nested observational study. BMJ 2004;328:444.

15. Kotwani A, Wattal C, Katewa S, Joshi PC, Holloway K. Factors influencing primary care physicians to prescribe antibiotics in Delhi India. Fam Pract 2010;27:684-90.

16. Hart AM, Pepper GA, Gonzales R. Balancing acts: Deciding for or against antibiotics in acute respiratory infections. J Fam Pract 2006;55:320-5.

17. Giblin TB, Sinkowitz-Cochran RL, Harris PL, Jacobs S,
Liberatore K, Palfreyman MA, et al. Clinicians' perceptions of the problem of antimicrobial resistance in health care facilities. Arch Intern Med 2004;164:1662-8.

18. André M, Vernby A, Berg J, Lundborg CS. A survey of public knowledge and awareness related to antibiotic use and resistance in Sweden. J Antimicrob Chemother 2010;65:1292-6.

19. Holloway KA, Gautam BR, Harpham T, Taket A. The influence of user fees and patient demand on prescribers in rural Nepal. Soc Sci Med 2002;54:905-18.

20. Kotwani A, Wattal C, Joshi PC, Holloway K. Knowledge and perceptions on antibiotic use and resistance among high school students and teachers in New Delhi, India: A qualitative study. Indian J Pharmacol 2016;48:365-71.

21. David KJ. Patients who demand antibiotics and the doctors who prescribe them. Emerg Med News 2002;24:15-6.

22. Chandy SJ, Mathai E, Thomas K, Faruqui AR, Holloway K, Lundborg CS, et al. Antibiotic use and resistance: Perceptions and ethical challenges among doctors, pharmacists and the public in Vellore, South India. Indian J Med Ethics 2013;10:20-7.

23. Kotwani A, Wattal C, Joshi PC, Holloway K. Irrational use of antibiotics and role of the pharmacist: An insight from a qualitative study in New Delhi, India. J Clin Pharm Ther 2012;37:308-12.

24. Abera B, Kibret M, Mulu W. Knowledge and beliefs on antimicrobial resistance among physicians and nurses in hospitals in Amhara region, Ethiopia. BMC Pharmacol Toxicol 2014;15:26.

25. Ministry of Health \& Family Welfare. Government of India. Gazette Notification GSR 588 (E) dated 30-08-2013. Available from: http://www.cdsco.nic.in/writereaddata/588E30thAug2013.pdf. [Last accessed on on 2017 Aug 8].

26. Ministry of Health and Family Welfare. National Policy on Containment of Antimicrobial Resistance. Directorate General of Health Service. New Delhi: Government of India; 2011. Available from: http:/ / www.ncdc.gov.in/ab_policy.pdf. [Last accessed on 2017 Mar 04].

27. Laxminarayan R, Chaudhury RR. Antibiotic resistance in India: Drivers and opportunities for action. PLoS Med 2016;13:e1001974.

28. Holloway KA, Rosella L, Henry D. The impact of WHO essential medicines policies on inappropriate use of antibiotics. PLoS One 2016;11:e0152020.

29. Ministry of Health and Human Welfare. Press Release: India Develops National Action Plan to Combat Antimicrobial Resistance. Delhi: Government of India; 19 April, 2017. Available from: http://www.pib.nic.in/newsite/PrintRelease. aspx?relid=161160. [Last accessed on 2017 Jun 06].

30. Kotwani A, Holloway K. Access to antibiotics in New Delhi, India: Implications for antibiotic policy. J Pharm Policy Pract 2013;6:6. 